\title{
OS CASOS DE CURA DIVINA E A CONSTRUCÃO DA DIFERENCA,
}

\author{
Simoni Lahud Guedes \\ Universidade Federal Fluminense - Brasil
}

Resumo: Estudando os processos de transmissão do "saber prático", entre os trabalhadores urbanos, discute-se o lugar e o significado dos "casos" retidos na memoria familiar e local. Tais "casos", ainda que particulares e específicos, representam a retenção e o recorte de determinadas experiências vividas na memória, atestando a importância coletiva das idéias e valores que colocam em atuação. Sua retenção, circulação e transmissão constitui-se numa pedagogia, extensamente utilizada nos processos de construção das identidades. Neste artigo são analisados "casos de cura divina", provenientes de material etnográfico produzido pela autora, classificados em dois tipos principais: os "casos de desengano" e os "casos de doenças espirituais". Através deste material empírico discute-se a questão da inter-relação e do confronto de saberes no que se refere às interpretações do corpo e da doença, sob a forma "nativa" da oposição entre o "saber prático e saber teórico". A análise destes "casos" permite, além disso, refletir sobre o lugar da oralidade nas sociedades em que a escrita e a literalidade conformam os modos dominantes de conhecimento, contribuindo, simultaneamente, para a discussão sobre os processos de construção da memória familiar e local.

Abstract: Studying the process of transmission of "practical knowledge" among urban workers, it is discussed the place and meaning of narrated "cases" that are regarded as exemplar. Such "cases", are taken as representative of events and as memory of life experiences. The record of these cases, their circulation and transmission builds up a pedagogy that works as a way of constructing identities. In this paper,

\footnotetext{
* Trabalho originalmente apresentado na II Reunión de Antropología del Mercosur, de 11 a 14 de novembro de 1997, em Piriápolis, Uruguai, no GT 12, Corpo, Saúde e Doença, coordenado por Ceres Víctora e Daniela Knauth. Agradeço os comentários de todos os participantes do grupo, em especial à debatedora Ondina Fachel Leal e a Jane Russo.
} 
are analyzed cases of "miraculous healing", classified in two main categories: as cases of "desengano" [hopeless cases] and cases of spiritual healing. Through this empirical material, I discuss the interrelation and the confrontation between different knowledge regarding the body and the disease, within its "native" connotation of "practical and theoretical knowledge". The analysis of these cases also allows us to think about the place of orality in societies where the literacy is a dominant mode of knowledge, at the same time that contributes to a discussion about the construction of the familiar and local memory.

Os estudos antropológicos, nas sociedades modernas, contemporâneas, têm problematizado, através de perspectivas teóricas distintas, as fronteiras culturais distinguíveis em seu interior. Uma das questões mais importantes que atravessam esse campo de debates refere-se à coexistência de códigos culturais diversos, partilhados e incorporados desigualmente por diferentes segmentos sociais, gerando complexos processos simultâneos de identificação e diferenciação (cf. Velho, 1981, 1994). Nas análises nestes contextos, é preciso considerar, por um lado, que, sob nenhuma hipótese, é possível postular quer a existência de unidades sócio-culturais discretas e em relação unívoca, quer o equilíbrio, em termos de potencialidade de imposição de significados entre os sistemas culturais em correlação. Por outro lado, sabemos que o potencial desigual que as classes e segmentos sociais têm para difundir e legitimar sua visão de mundo, ${ }^{1}$ insere-se num intrincado jogo de forças em que mesmo os mais despossuídos operam na afirmação e recriação de sua diferença, reapropriando-se dos esquemas que lhes permitem interpretar de modo específico suas experiências de vida. O quadro resultante, muitas vezes desalentador para o analista, é atravessado por múltiplas interseções, esboçando o próprio processo permanente de reposicionamento de significados e recriação de fronteiras característico de qualquer processo cultural em andamento.

Estas considerações não devem, contudo, nos levar a reeditar as teorias culturais das "colchas de retalhos", negando a sistematicidade das culturas nas sociedades modernas contemporâneas ou afirmando a fragmentação completa

1 Esta questão é extensamente trabalhada na sociologia de Pierre Bourdieu (ver, por exemplo, Bourdieu 1982), perspectiva que, sob este aspecto, inspira o recorte deste trabalho. 
dos indivíduos num mundo multifacetado. ${ }^{2}$ Propõem-nos, isso sim, abordagens mais sofisticadas que permitam compreender como os esquemas culturais são sustentados pelas pessoas, orientando leituras relativamente coerentes do mundo, enquanto, simultaneamente, reproduzem-se em meio a seu próprio processo de mudança, num contexto pleno de alternativas. O primeiro passo é, mais uma vez, do ponto de vista metodológico, não reificar as culturas. Operar, portanto, num nível dessubstantivado de abordagem (Duarte, 1986), que permita reconstruir sistemas simbólicos coerentes em seus princípios geradores, evidenciando os significados que se constroem pela posição diferencial dos signos uns em relação aos outros, mas que não se apresentam in totum na consciência dos atores sociais ou nas objetificações sociais. Constituem-se, antes, em valores de referência que podem ser agregados, como na expressão de Dumont (1985), como configurações de idéias-valores. É neste plano, por exemplo, que creio ser possível falar de uma "cultura de classe trabalhadora" - contexto principal dos fenômenos do discurso que apresento aqui - referindo-me às idéias e valores articulados que orientam a visão de mundo e a atuação dos que se identificam como trabalhadores, diferenciando-os e opondo-os aos que eles vêem como "outros".

Mas tais visões de mundo realizam-se, efetivamente, como significados no mundo. Ou melhor, como diz Marshall Sahlins ao implodir a oposição teórica entre estrutura e evento, correm a todo momento "o risco da ação cultural, que é o risco das categorias em referência. As pessoas colocam, na ação, seus conceitos e categorias em relações ostensivas com o mundo.” (Sahlins, 1990, p. 185). ${ }^{3}$ É recomendável, assim, uma abordagem que vise atentar para aqueles domínios e aspectos da vida social que permitam o acesso às "categorias

\footnotetext{
2 Gilberto Velho (1994, p. 29) tem abordado esta questão através das noções de províncias de significados e potencial de metamorfose: "Essa permanente latência implica o que poderíamos chamar de 'potencial de metamorfose’, distribuído desigualmente por toda a sociedade. O repertório de papéis sociais não só não está em um único plano, mas a sua própria existência está condicionada a múltiplas realidades. Com isso, talvez possamos escapar de falsos problemas ditados por uma visão linear da experiência sociocultural.” Chama a atenção, ainda, para o fato de que tal complexidade é da própria natureza do social, tornando-se apenas mais evidente nas sociedades moderno-contemporâneas.

3 "A ordem cultural, enquanto um conjunto de relações significativas entre categorias, é apenas virtual. Existe meramente in potentia. Portanto, o significado de qualquer forma cultural específica consiste em seus usos particulares na comunidade como um todo. Mas este significado é realizado, in presentia, apenas como eventos do discurso ou da ação. O evento é a forma empírica do sistema.” (Sahlins, 1990, p. 190).
} 
no mundo", ou seja, que coloquem em foco a complexidade dos confrontos em que estão imersos os sistemas simbólicos.

Trago, neste artigo, algumas observações acerca de uma forma específica de fixação de experiências relativas ao corpo, à saúde e à doença, entre trabalhadores urbanos da região metropolitana do Grande $\mathrm{Rio}^{4}$ - um aspecto de sua memória familiar e local - classificável, segundo penso, justamente como sua reflexão acerca de suas "categorias no mundo": são os relatos que agreguei, seguindo denominação encontrada aqui e acolá nos estudos antropológicos, como "casos de cura divina". ${ }^{5}$

II

Pontuando histórias de vida e familiares, entrevistas ou conversas informais, tendo apenas o pesquisador como interlocutor ou congregando mais pessoas da família e do local, destaca-se, na pesquisa com trabalhadores urbanos no Grande Rio, o interesse e a importância que atribuem aos "casos", grande conjunto de episódios memoráveis dentre os quais incluem-se os "casos de cura divina”. Venho já, há algum tempo, selecionando, contextualizando e analisando estes “casos” (Guedes, 1985, 1994, 1997).

4 O material aqui trabalhado foi produzido dentro de dois grandes trabalhos de pesquisa que realizei. O primeiro (Guedes, 1985) no interior de um projeto multidisciplinar, coordenado pela Dra Anamaria Tambellini na Fundação Oswaldo Cruz, Rio de Janeiro, no qual estive encarregada do projeto antropológico, versando especificamente sobre os diferentes procedimentos terapêuticos acionados por operários metalúrgicos. Foi realizado em Mesquita, na ocasião distrito de Nova Iguaçu, um dos municípios da região metropolitana do Grande Rio de Janeiro. O segundo (Guedes, 1997) é parte do material produzido na pesquisa para minha tese de doutoramento no Programa de Pós-Graduação em Antropologia Social, da UFRJ, produzido na região de Neves, no município de São Gonçalo, na mesma região metropolitana. São, ambos, municípios densamente povoados, registrando, inclusive, populações acima de um milhão de habitantes cada um. Nas duas pesquisas, recortei um segmento estável de trabalhadores urbanos, enraizado ou buscando enraizar-se em locais de moradia, valorizando a estabilidade conjugal e registrando, em termos de inserção no mercado de trabalho, histórias profissionais que alternam períodos de trabalho industrial, trabalho no comércio, além de períodos de desemprego, subemprego e "trabalho por conta própria”.

5 Estes fenômenos têm sido chamados na literatura antropológica, alternativamente, como de "cura divina” ou “cura milagrosa”. Neves (1984) e outros autores preferem a segunda denominação. Eu preferi a primeira, por me parecer mais geral, e cobrir os dois tipos de casos que distingui, sem necessariamente envolver a categoria "milagre", implícita em alguns casos, mas não em todos. Aliás, a categoria “milagre” que não encontrei nas pesquisas referidas, utilizada na narração dos casos, pode recobrir significados bem específicos, que precisam ser investigados, como o demonstra Zaluar (1980).

Horizontes Antropológicos, Porto Alegre, ano 4, n. 9, p. 47-62, out. 1998 
“Casos” são relatos mais ou menos cristalizados de determinados episódios, considerados dignos de ser retidos, ocorridos na vida do narrador ou de pessoas que são classificadas como “conhecidas”. Esta é, aliás, uma de suas características mais marcantes: seus principais atores são necessariamente nomeados e situados. Isto se constitui num critério fundamental para o valor do "acontecido". Quanto maior a proximidade dos atores e a possibilidade de qualificá-los - sendo a moradia no local e/ou a existência de relações de parentesco próximas dos seus mais importantes atributos - maior veracidade lhe é concedida. Contados, em geral, na primeira pessoa, nunca são relatos anônimos ou referentes a acontecimentos sociais que afetaram muitas pessoas simultaneamente, distinguindo-se assim de uma memória social, no seu sentido mais estrito. Ao contrário, versam sobre acontecimentos singulares na vida das pessoas como, por exemplo, a história de uma improvável conjugação de eventos que permitiu ao narrador conseguir um determinado emprego, uma incomum ida ao teatro, mortes inesperadas, viagens insólitas, “traição” de noivas ou namoradas e assim por diante. Na verdade, tudo pode se transformar num "caso", desde que contenha os elementos extraordinários que o tornem destacável pois sua matéria-prima são as vicissitudes do viver.

Certamente, há algumas áreas mais propícias à proliferação de “casos” que outras, e, sem dúvida, os episódios marcantes referentes às doenças, interrupções que são da sucessão do cotidiano, têm uma potencialidade singular nesse sentido. Estão, também, entre os episódios cercados de maior dramaticidade na narração, aspecto bastante considerável pois o conjunto dos “casos” não se caracteriza, absolutamente, por este tom. Há “casos” engraçados, outros apenas curiosos, outros ainda, como neste conjunto, extremamente sérios e narrados com emoção, cuidado e circunspecção.

Definindo-os, portanto, primariamente, como narrativas a respeito de fatos extraordinários acontecidos com o próprio narrador ou com pessoas conhecidas, é necessário ainda acrescentar outra característica, aparentemente óbvia, mas que tem implicações importantes. Trata-se do fato de pertencerem ao domínio da oralidade e só pela repetição contextualizada serem retidos, partilhando, por conseguinte, uma série de características dos processos de transmissão oral. Sua fixação implica, pois, ao mesmo tempo, na persistência de contextos em que se mantenham como interessantes, ou seja, novos eventos sociais, empiricamente distintos, em que possam ser repetidos. São cristalizados, assim, em narrativas frequentemente reproduzidas que, por esta 
mesma via, podem ser apropriadas coletivamente no âmbito restrito do círculo de relações primárias - família, vizinhos, amigos, “colegas” do local, companheiros de trabalho - compondo um estoque simbólico de situações especiais que assumem uma qualidade de exemplaridade. O conjunto de "casos" disponível numa determinada rede de relações sociais primárias é atualizado pelo simples abandono e esquecimento de alguns e incorporação de outros e, muito possivelmente, por alterações sutis de significados nos signos que incorporam (cf. Goody; Watt, 1968). Sob este aspecto, podem ser considerados tanto mais representativos ou maleáveis (no sentido de abertura a novas interpretações) quanto mais se refiram a acontecimentos ocorridos há muitos anos, atestando a continuidade do interesse que apresentam.

Posso, desse modo, resumir os fenômenos da oralidade de que trato aqui - os “casos de cura divina” entre trabalhadores urbanos no Grande Rio - como a cristalização da narrativa de determinados episódios de cura de doenças graves. ${ }^{6}$ São "casos”, assim, num duplo sentido: num, porque seu referencial são os episódios ocorridos na vida das pessoas ou de alguém que conhecem; noutro, porque passam a ter uma versão narrada cuja função é reproduzi-los, de uma maneira mais ou menos semelhante, em diversas situações. Podem ser destacados, no conjunto dos "casos" que retêm, como de "cura divina" porque, de um modo ou de outro, fazem intervir planos de realidade em que atuam forças e entidades invisíveis, com as quais os homens partilham o mundo e que, de um modo geral, são dotados de poder superior ao dos homens. Acresça-se que a retenção destes “casos” pressupõe que foram bem sucedidos, selecionados dentro de um conjunto maior de experiências de insucesso desde que todos os "casos" relatados, sem exceção alguma, conduziram à cura. Não há reprodução de qualquer "caso" no qual se tenha buscado a intervenção divina e que tenha redundado em fracasso. Pode-se supor, inclusive, que tal possibilidade os conduz ao abandono pela memória. O máximo que é retido, neste sentido, são episódios de insucesso precedentes à cura, quando esta ainda não é obtida.

\footnotetext{
6 Aliás, como demonstrei (Guedes, 1985), para os trabalhadores a categoria “doença” só assume seu sentido pleno quando afeta sua capacidade de trabalho, não merecendo de fato este rótulo os incômodos de que se vêm acometidos cotidianamente mas que não interferem no seu fazer. "Doenças que se trata andando”, como dizem, não são propriamente “doenças”. "Doença grave”, portanto, é, nos termos desta cultura, um pleonasmo.
} 
Relatos deste tipo aparecem, em geral, de modo espontâneo nas relações com o pesquisador mas nunca nos primeiros contatos, como é possível ocorrer com alguns outros “casos”, de natureza diversa. Só depois de estabelecida uma relação relativamente estável, uma certa confiança na pessoa que investiga, é que são confiados à sua guarda. Na maioria das vezes, mesmo quando são contados por mais de uma pessoa, recuperando a própria possibilidade de que a linguagem coloque em ação forças não controláveis, são contados num tom de voz mais baixo, cercados de cuidados, em especial na referência a certas categorias que têm um sinal de perigo, como “macumba”. O pesquisador é solicitado a desligar o gravador algumas vezes ou interrogado sobre a propriedade de gravar o que vai ser relatado. É claro que tais cuidados falam do lugar especial que estes episódios ocupam mas falam também da relação com um outro tipo de saber, o "saber teórico", com o qual identificam o pesquisador. Esta oposição, estabelecida inclusive pelo seu próprio modo de retenção, não é o menor dos seus significados.

Os "casos de cura divina" aparecem sob duas construções principais: os “casos de desengano" e os "casos de doenças espirituais”. As duas formulações narrativas guardam diversas semelhanças entre si mas apresentam algumas diferenças, que buscarei mostrar, ao colocarem em atuação modos ligeiramente distintos de colocar suas "categorias no mundo", expressando versões possíveis da releitura do "risco da ação cultural” (Sahlins, 1990).

III

Não há dúvida de que nos eventos comunicativos orais, o contexto de sua produção e o desempenho do narrador e dos ouvintes é absolutamente fundamental para a compreensão de seu lugar e de seu significado (Rondelli, 1993). Trabalhei, em outro texto (Guedes, 1985) mais detalhadamente este aspecto. O que pretendo aqui é trazer à discussão uma interpretação destes fenômenos, tal como se apresentam nos discursos, com relação a uma distinção central para a construção do ser trabalhador: a oposição que estabelecem entre "saber prático” e "saber teórico”. Ou, em seus próprios termos, “teoria”, da qual estão excluídos e "prática”, seu apanágio. Sob tal ângulo, os "casos de cura divina” são tematizações da diferença e afirmações de um saber e de um poder que se opõe ao saber-poder letrado. Esta diferença e este saber-poder não se 
constroem, apenas, na invocação de uma ordem divina. A crença num mundo sobrenaturalizado atravessa diversos segmentos da sociedade brasileira, como alguns autores já têm demonstrado (cf., por exemplo, DaMatta, 1985; Velho, 1994), ${ }^{7}$ disponibilizando difusa e desigualmente as pessoas para seu acionamento, particularmente nas situações de crise de vida. A aposta aqui, como diria Sahlins, é um pouco mais alta: aposta-se na eficácia das interpretações práticas e na possibilidade que têm os despossuídos de atuar efetiva e eficazmente sobre o mundo em que vivem, reapropriando-se de corpos e símbolos, desapropriados pelo processo de trabalho sob o capitalismo. ${ }^{8}$

Para que isso ocorra, é necessário reconhecer, como ponto de partida destas construções orais, o saber médico como a instância legitimada para falar sobre a doença, condição para que possa ser efetuada sua desqualificação, expondo os limites de seu saber-poder. Estabelecendo, assim, o terreno da alteridade diante do qual se situam, estão livres para elaborar novas interpretações. Esta desqualificação é obtida de modo um pouco diferente nos "casos de desengano" e nos "casos de doença espiritual”.

Nos "casos de desengano", o terreno da alteridade diante do qual vão construir seu relato é desenhado pela situação inicial em que o individuo adoecido não encontra mais recursos na medicina, ou, em seus próprios termos, é “desenganado” pelos médicos. Pressupõe um longo processo de adoecimento e um calvário de terapias Sem dúvida, a noção de "desengano" é muito complexa e é necessário contextualizá-la, tal como o faz Neves (1984, p. 45-46) para o caso específico dos adeptos da Assembléia de Deus. Contudo, a noção tem ao menos um referencial comum, sempre que empregada: "estar desenganado" ou "desenganar alguém” significa que todos os recursos médicos disponíveis, reais e supostos, foram esgotados no tratamento daquela pessoa doente. Deste modo, seu emprego remete, necessariamente, ao momento percebido como de confluência de dois processos: o primeiro, encerrado, trata dos diversos procedimentos médicos buscados para curar o doente; o segundo, que só pode ser disparado com o término do primeiro, trata do processo de

\footnotetext{
Ao contrário, como demonstrei (Guedes, 1985), pude encontrar diversos casos em que o episódio de "cura divina" sobrevém a pessoas céticas e que, mesmo após a obtenção do que reconhecem como benefício, procuram se manter afastadas de qualquer religião ou daquela específica que a curou. Uma mulher, nesta situação, me disse: "não acredito, mas fui obrigada a acreditar".

8 Maria Andréa Loyola (1984) elabora, a partir da análise de três confissões religiosas e de diversas ofertas de terapias “divinas”, em município do Grande Rio, publicada em extenso trabalho, a perspectiva de que o conjunto destas práticas representa, de modos diversos, formas de resistência ao poder médico.
} 
“cura divina”. Trata-se da legitimação dos procedimentos que se seguirão pela denegação, por limitação de saberes, da racionalidade médica. O ponto de partida é, assim, sempre a reprodução da fala da medicina. Aplicar a alguém o rótulo de "desenganado", portanto, é simplesmente utilizar uma categoria que sumariza a expressão "estar desenganado pelos médicos e pela medicina em geral”. Além disso, para que a credibilidade do relato seja sustentada, não basta o parecer de um único médico para o reconhecimento da situação como de “desengano”. É necessário afirmar que vários atestaram o fato, que todos os recursos médicos foram esgotados e assegurar a qualificação dos que o fizeram. É preciso, portanto, conhecer e operar com os critérios de legitimação deste "outro" campo de saber, qualificando suas práticas.

As falas abaixo são demonstrativas da construção deste confronto, referindo-se as duas primeiras a "casos de desengano" e a terceira a um "caso de doença espiritual”:

Desenganaram ela e ela não tinha mais pra onde correr. [...] então se desesperou, desenganada mesmo pelo médico, ele não era medicozinho qualquer não, médico de rico, eles procuraram médicos, são ricos... (Casal de trabalhadores com cerca de 60 anos, ambos, relatando caso de desengano curado na sua Igreja Metodista).

Isso aconteceu com meu filho Sílvio. Ele foi internado no hospital com um médico muito bom, doutor Carlos, família excelente. Quando minha esposa levou o Sílvio pra ser internado, já com ordem do INAMPS, o doutor Carlos tinha perdido a sobrinha naquela manhã. Ele conheceu a minha esposa, estudaram juntos ali em Nilópolis, mas ela casou e ele se formou em medicina. E então os dois se lembraram e então ele disse pra ela: "Olha, dona Dirce, eu lutei com a minha sobrinha a noite toda e ela morreu. Agora eu prometo lutar pelo seu filho também." A boa-vontade de um médico. Mas esse mesmo doutor Carlos, após sete meses que o meu filho ficou internado lá, disse pra minha esposa: “Olha, seu filho está de alta. Você leva o seu filho que ele está predestinado a morrer, amanhã pode vir aqui apanhar o atestado de óbito, não tem jeito mais.” (Mecânico, 42 anos, relatando, junto com sua esposa, doença de filho com meses de idade, ocorrida nove anos antes, e que foi curada por suas orações).

Ih, eu corri muito médico. Eu fui na Alcindo Guanabara na Cinelândia, ali é que os médicos [ficam], tem edifício de médicos. Mas eu corri muito médico, corri muito médico ali. Nada. Nada. Um dizia que era não sei o que, que era catarata, 
catarata num era, eu tava com a vista limpa! Aí eu quis me matar... Eu estava desesperado. (Trabalhador aposentado, 80 anos, relatando sua cegueira, aos 40 anos, curada por um "curandeiro”).

Desse modo, enquanto eventos comunicativos orais, todos estes "casos" estão referidos ao saber e à prática médicos. Pode ser que, como aponta Neves (1984) uma variável importante a ser considerada na avaliação destes "casos” sejam os intensos ruídos na comunicação entre médicos e pacientes, gerando leituras equivocadas de seus diagnósticos. São conhecidos os segredos que cercam o fazer médico, expressos numa escrita e numa oralidade intencionalmente esotéricas, de modo a preservar a valia do seu saber. ${ }^{9}$ Entretanto, no domínio em que estou operando, o que importa é o modo como são retidos na memória familiar e local, reproduzidos e transmitidos, compondo um estoque simbólico que atua decisivamente na construção das diferenças.

É também o estabelecimento de uma certa incompetência do saber médico, como se vê, que gerará as formulações narrativas que considerei produtivo chamar de "casos de doenças espirituais". Sem necessariamente partir da noção de "desengano" - devolução incompetente do corpo doente à família -, mas podendo eventualmente incluí-la, caracterizam-se por elaborar um ponto de partida narrativo em que uma doença crônica e incapacitante se instala, prolonga-se por tempo demasiado e mostra-se refratária aos tratamentos oferecidos pela medicina. O que caracteriza, entretanto, tais relatos, é que a ênfase do discurso, ao invés de ocorrer na situação inicial, ocorre nos longos desdobramentos que levam à desqualificação do diagnóstico médico, pela subtração da causa do mal ao território físico. São mais propriamente, nesse sentido, doenças “físico-morais" (Duarte, 1986), invocando um nível de realidade sobre o qual a racionalidade médica não pode atuar, num processo, creio eu, já suficientemente explorado na antropologia brasileira. Se, nos "casos de desengano”, um difuso poder divino se manifesta através de orações coletivas, no contexto familiar ou de congregações religiosas, produzindo a cura de doenças que podem ser apenas físicas, momento relatado concisamente, quando a refração ao tratamento é claramente associada à existência de doença espiritual, o "caso" se desdobra e se complexifica, em episódios detalhadamente

9 Este aspecto, aliás, é o mais rico do trabalho de Boltanski (1979), complicado sob outros aspectos por uma utilização teoricamente inadequada do rótulo “medicina popular”. 
narrados compondo um drama no qual atuam diversas pessoas conhecidas, da família e da vizinhança. Aqui, será mais difícil suprir a falta do relato, tal como se apresenta, pois a narração, sempre muito longa e detalhada, às vezes aparentemente apenas prolixa e repetitiva, é, de fato, parte constituinte do evento tal como é retido pois, muito mais que nos "casos de desengano", a identificação de uma doença espiritual e, finalmente, sua cura, são, antes de tudo, fenômenos que só podem ser compreendidos na recuperação de densos complexos de relações sociais, sua causa última: o mal, assim como o bem, é provocado pelos que estão próximos. ${ }^{10}$ Instaura-se, como pressuposto da cura, a necessidade de identificação da origem do mal, o que quer dizer, uma análise fina e cuidadosa das relações em que o ser doente está envolvido, numa espécie de inventário das paixões humanas. O diagnóstico, a cargo de diferentes agentes religiosos, supõe um inquérito, de que trago um pequeno exemplo:

Aí eu fui em Rio Bonito, tinha um senhor escuro lá, até ele ia ser padrinho de minha mulher, aí eu fui lá, ele pegou, me perguntou se eu era noivo. Ele olhou pra mim, perguntou: ué, você está cego? O que que você arranjou? Eu num arranjei nada não se nhor, eu não sei. Você é noivo? Eu disse: sou, sim senhor. Essa noiva que você é noivo, você tomou ela de algum rapaz ou ela tomou você de alguma moça? Eu disse: bom, essa garota que é minha noiva, fui eu que tomei ela de um rapaz que tava namorando ela. Eu era atentado! Eu só gostava de namorada dos outros! (Trabalhador aposentado, de 80 anos, referido em página anterior).

E, embora possam envolver uma série de procedimentos ritualizados para reverter a doença, são especialmente interessantes como eventos comunicativos pois têm na palavra que desvenda sua terapia maior. O exemplo seguinte é quase um paradigma destas atuações:

Aí eu falei pra ela: deixa a minha vida em paz! [...] Depois que eu falei isso com ela, que beleza! Aí o meu pé ficou bom! Andava tudo ferido! [...] Depois que eu falei com ela, parece que quebrou o encanto dela. Parece que quando uma pessoa faz mal a gente, a gente fala com ela e acabou aquilo. Positivo. Fiquei bom. (Operário solteiro, 50 anos, relatando doença espiritual ocorrida 20 anos antes, provocada por uma mulher).

10 Bem à moda Azande (Evans-Pritchard, 1978). 
Desse modo, os “casos de cura divina”, em particular os de “doença espiritual”, atualizam e reafirmam a diversidade de práticas associadas aos modos de dizer as relações sociais. Mantendo estreita sintonia com uma cultura na qual a pessoa constrói-se como um resultado dos diferentes lugares que ocupa na família, no parentesco, na vizinhança, nas relações de trabalho, os "casos de cura divina” são, claramente, tematizações acerca do estado destas relações nos termos dos valores e das idéias que orientam suas visões de mundo.

IV

Para além do que dizem, estes casos afirmam e ensinam uma cultura, uma diferença e uma identidade pelo próprio modo de dizer. Não se apresentam dissociados da sociabilidade cotidiana, sendo exemplarmente recordados sempre que necessário ou a cada vez que se apresenta a oportunidade. Muitos deles são registrados varias vezes, no material de campo, sendo contados e recontados, em contextos familiares e locais diversos. São singulares e pessoais, mas não confessionais, sendo conhecidos de todos os próximos. Conhecer alguém é também, de certa forma, conhecer seus “casos”. Deve lembrar ainda que, embora sejam, em geral, dos mais dramáticos, situam-se num conjunto muito mais amplo de experiências exemplares que alimentam as interações cotidianas. Ensinam, portanto, a valorizar a experiência como forma de saber, logo, de atuar.

Fazem parte do repertório coletivo, difusamente ensinado e difusamente aprendido. Há alguns significativos relatos que destacam, exatamente, que os modos de aprender esta visão de mundo, sendo os mesmos pelas quais ela se memoriza - experiências vividas, são percebidos como um “dom”, como algo que se apresenta repentinamente e que não depende de nenhum ensinamento explícito para ser incorporado. Aprender que se pode identificar "doenças espirituais" e curar "desenganados” é descobrir que se partilha uma herança moral, é alinhar-se junto aos seus:

Quando é que a senhora descobriu que podia rezar as pessoas?

Você vai achar até interessante. Eu tinha os meus sete anos, morava aí dentro, e aqui pra dentro, era muito humilde, tinha muita gente pobrezinha, muita gente com criança. Eu estudava lá dentro, um coleginho que tinha. Então, um dia... a minha família era toda espírita, já morreram, eu estava sentada assim, num 
banquinho, tomando café, arrumadinho pra ir pro colégio, aí passou uma senhora daí de dentro, com uma criança muito mal, a criança vomitando, evacuando e com muita febre. Aí, ela passou... Eu sempre fui assim, muito cativa, eu gosto de ajudar. Então eu virei, eu disse assim: “Ué, o que essa criança tem?” Aí, ela virou e disse assim: "Ah, minha filha, não deixou eu dormir a noite toda, vomitando, evacuando e com febre.” A minha mãe sempre contava isso para os outros e alguma coisa eu ainda lembro bem. Aí eu virei e disse assim: "Vem cá." Mamãe virou e disse assim: "Maria, o que é isso?” Eu disse: "Mamãe, eu vou rezar essa criança porque essa criança está passando mal.” Aí mamãe disse assim: "E você lá sabe rezar?” Eu disse: “Olha, eu sei que eu vou rezar e vai ficar boa." Aí, minha avó, lá de dentro, disse assim: "Maria, Maria, o que é isso?” "Não, vovó, vou rezar a criança.” Aí passei a mão na faca, fui lá dentro do mato, apanhei três galhinhos de rezar, botei um atrás da orelha. [...] Eu sei que eu rezei a criança toda. Rezei, acabei de rezar, e ensinei remédio. Ai a minha mãe virou e disse assim: "Pelo sim pelo não a senhora leva essa criança para o pronto-socorro.” Ela disse: “Não senhora, não vou levar não. Eu vou pra casa e vou fazer o que ela mandou”. [...] A criança ficou boa. (Dona Maria, esposa de jardineiro aposentado, 62 anos, uma das rezadeiras mais prestigiadas de um dos bairros estudados).

Este saber que se apresenta travestido nos eventos e atuações memoráveis, destacados do curso contínuo do cotidiano, compõe, no seu conjunto, uma pedagogia. Expõe, através do que conta, do que retém na memória pessoal, familiar e coletiva, uma visão de mundo, oferecendo os princípios simbólicos que propiciam a leitura do normal e do extraordinário que a vida apresenta. Expõe e propõe sentido, enfim. Expressa, ao mesmo tempo, uma aguda valorização da comunicação oral, forma primordial da sociabilidade e da socialização, realizada através da proliferação dos “casos” que transformam experiências individuais em saberes coletivos.

A eficácia atribuída explícita e implicitamente à comunicação oral, como forma de intervir e modificar o mundo e ainda, de registrar o dito e feito, não é sem consequências na avaliação que os trabalhadores fazem de um processo de educação institucionalizado que, explicitamente, baseia-se no saber que denominam "teórico" e valoriza as formas escritas. ${ }^{11}$ Percebido genericamente como base do saber dominante, do qual estão excluídos, aprofundam e

11 Embora, como Kant de Lima (1997) vem demonstrando, no Brasil, no próprio campo da produção erudita, é fundamental a valorização da oralidade, inclusive como forma de reter a exclusividade do conhecimento. 
reforçam sua distância deste outro conhecimento, quando se pensam capazes de se mover apenas nos caminhos da oralidade.

Num outro registro, acho ainda importante anotar, como alguns pesquisadores têm sugerido (ver, por exemplo, Feldman, 1995, e, para o Brasil, Kant de Lima, 1997) que a oralidade, além de ser inevitável em qualquer processo cultural, assume formas e significados específicos em tradições diversas, não se limitando às formas coloquiais das conversações do cotidiano a que algumas vezes a relegamos. Decerto, os trabalhos antropológicos, inscrevendo e transcrevendo a oralidade, têm tido a possibilidade de identificar, dentro das interações sociais, na qual os pesquisadores são incluídos, valorações, construções e significados distintos dos processos de interação e transmissão oral, considerando, inclusive, as complexas relações estabelecidas entre o oral e o escrito. Vale ressaltar que recortamos um campo que, de fato, é o da inter-relação entre diferentes formas de oralidade e diferentes efeitos e apropriações da cultura escrita (cf. Goody, 1988) e uma abordagem mais sistemática deveria ir em busca desta relação.

Os "casos” valorizados pelos trabalhadores, não sendo decerto um gênero oral particular, são, todavia, um efeito de uma cultura que tudo pensa e tudo organiza a partir das experiências das pessoas. Só tem valor o que foi experimentado, praticado, vivido, conhecido e que, por isso, é passível de ser dito, redito e socializado nos âmbitos restritos em que o conhecimento mútuo permita reter seu valor. Experiências, se descontextualizadas, se transformadas em relatos sem carne e osso, perdem seu poder de convencimento. É um mundo em que as referências culturais são aprendidas e ensinadas incorporadas nas atuações das pessoas. Logo, para o antropólogo, a análise destes “casos” fixados na memória familiar e local pode ser uma eficiente estratégia metodológica para abordar o sistema cultural em sua abertura para o mundo, testado e colocado "em risco".

\section{Referências}

BOURDIEU, P. A economia das trocas simbólicas. São Paulo: Perspectiva, 1982.

BOLTANSKI, L. As classes sociais e o corpo. Rio de Janeiro: Graal, 1979. 
DAMATTA, R. Espaço: casa, rua e outro mundo: o caso do Brasil. In: DAMATTA, R. A casa e a rua. São Paulo: Brasiliense, 1985.

DUARTE, L. F. D. Da vida nervosa nas classes trabalhadoras urbanas. Rio de Janeiro: Jorge Zahar Editores; Brasília: CNPq, 1986.

DUMONT, L. O valor nos modernos e nos outros. In: DUMONT, L. O individualismo: uma perspectiva antropológica da ideologia moderna. Rio de Janeiro: Rocco, 1985.

EVANS-PRITCHARD, E. E. Bruxaria, oráculos e magia entre os azande. Rio de Janeiro: Zahar, 1978.

GOODY, J. Domesticação do pensamento selvagem. Lisboa: Presença, 1988.

GOODY, J.; WATT, I. The consequences of literacy. In: GOODY, J. (Ed.). Literacy in tradional societies. Cambridge: Cambridge University Press, 1968.

GUEDES, S. L. Doença e cura: análise de processos terapêuticos buscados por operários metalúrgicos. Relatório de pesquisa. UFF, Fundação Oswaldo Cruz, 1985.

GUEDES, S. L. A exemplaridade do extraordinário: o lugar dos casos na memória dos trabalhadores. 1994. Comunicação apresentada. II Encontro Nacional de História Oral, Fundação Getúlio Vargas, Rio de Janeiro, 1994.

GUEDES, S. L. Jogo de corpo: estudo de construção social de trabalhadores. Niterói: Eduff, 1997.

FELDMAN, C. Metalinguagem oral. In: OLSON, D.; TORRANCE, N. (Org.). Cultura escrita e oralidade. São Paulo: Ática, 1995.

KANT DE LIMA, R. A Antropologia da academia: quando os índios somos nós. 2. ed. Niterói: Eduff, 1997.

LOYOLA, M. A. Médicos e curandeiros: conflito social e saúde. São Paulo: Difel, 1984. 
NEVES, D. P. As “curas milagrosas” e a idealização da ordem social. Niterói: Eduff, 1984.

SAHLINS, M. Ilhas de história. Rio de Janeiro: Jorge Zahar Editores, 1990.

VELHO, G. Projeto, emoção e orientação em sociedades complexas. In: VELHO, G. Individualismo e cultura: notas para uma antropologia da sociedade contemporânea. Rio de Janeiro: Zahar, 1981.

VELHO, G. Unidade e fragmentação em sociedades complexas. In: VELHO, G. Projeto e metamorfose: antropologia das sociedades complexas. Rio de Janeiro: Jorge Zahar Editores, 1994.

VELHO, G. Memória, identidade e projeto. In: VELHO, G. Projeto $e$ metamorfose: antropologia das sociedades complexas. Rio de Janeiro: Jorge Zahar Editores, 1994.

ZALUAR, A. Milagre e castigo divino. Religião e Sociedade, n. 5, p. 161-187, 1980. 